\title{
“Já Não Estamos Exatamente Vivos" - pareceres da CA/MJ e possíveis aproximações de Jamais o Fogo Nunca
}

\author{
Raquel Cristina Possolo Gonçalves \\ Universidade Federal de Minas Gerais \\ Jéssica Holl \\ Universidade Federal de Ouro Preto
}

\begin{abstract}
Já não estamos exatamente vivos (mortos, sim, mortos) depois dos cem, dos mil anos que tivemos que sobrelevar. Exaustos, com os ossos desencaixados, arruinados os rostos que tínhamos, você lembra? Ou talvez nunca tivemos, jamais houve rostos, não sei (Eltit, 2017, p.141).
\end{abstract}

\section{Introdução}

Em 1964, inicia-se no Brasil um período de regime ditatorial que duraria cerca de 21 anos. Através do golpe civil-militar, após assumirem o poder, os militares decretaram "atos institucionais" que subverteram a ordem constitucional anterior, buscando dar um "verniz" de legalidade (Pereira, 2010). Direitos foram suspensos e opositores ao regime foram perseguidos, vítimas de detenções extrajudiciais, torturas, desaparecimentos forçados. Dentre os opositores, as mulheres participaram ativamente da militância política, inclusive na luta armada (Teles, 2017, p. 63). No âmbito de uma crítica feminista à justiça de transição, afirma-se que algumas das violações a direitos humanos perpetradas por agentes de regimes autoritários são cometidas contra mulheres pelo fato de serem mulheres e por ousarem desafiar o papel de gênero que lhes fora atribuído, como constructo social. Essas violações têm sido tratadas através do uso da expressão violações baseadas em gênero, terminologia adotada nesse trabalho.

Nesse sentido, para reparar as graves violações de direitos humanos perpetradas durante o regime civil-militar, o Estado brasileiro implementou uma série de medidas transicionais. Dentre elas, a Comissão de Anistia foi criada pela Medida Provisória n ${ }^{\circ} 2.151$, convertida na Lei 10.559, de 13 de novembro de 2002. O objetivo de sua criação foi reparar moral e economicamente as vítimas de atos de exceção, arbítrio e violações aos direitos humanos que foram cometidas entre os anos 1946 e 1988. A sua implementação visava, então, regulamentar o artigo $8^{\circ}$ do ADCT da Constituição de 1988. Uma de suas principais finalidades é analisar e apreciar os requerimentos de anistia, a respeito dos quais emite pareceres para subsidiar as decisões do Ministro da Justiça sobre a concessão de Anistia Política. Apesar da disponibilização de publicações sobre a temática da justiça de transição no Brasil, em seu sítio eletrônico, não há uma publicação que reúna a completude dos pareceres já emitidos. Ainda, não se publicou um estudo sistematizado no que concerne à atuação da CA/MJ e sua abordagem da temática de gênero. Apesar dessa ausência, a CA publicou, no ano de 2013, o Livro dos Votos, no qual são publicizados cerca de 115 pareceres, exarados por seus conselheiros, em 
momentos diversos da atuação na Comissão. Os pareceres publicados foram elaborados ao longo dos anos de 2001 a 2012, a respeito de pedidos de concessão de anistia política de militantes mulheres e homens (Comissão da Anistia, 2013).

A implementação da Comissão de Anistia, apesar de ter se realizado afastada da discussão sobre gênero, representa um importante marco da busca pela verdade no país:

[...] esse foi um esforço com um pequeno número de beneficiários e um que, ao menos em termos de desenho, foi desconectado de outras medidas de justiça transicional. Embora o programa tenha sido desenhado como um mero mecanismo de distribuição, com o tempo adquiriu uma função importante de busca pela verdade. $\mathrm{O}$ caso contudo incentiva interessantes questões sobre a relação entre reparações e outras medidas de transição (De Greiff, 2006, p. XXIV).

Apesar dos esforços para reparar e para garantir um direito à memória e à verdade, objetivandose a máxima de que "não se esqueça para nunca mais aconteça", com o intuito de exemplificar, sem esgotar as ocorrências, apresentam-se dados a respeito de como o contexto de violações baseadas em gênero perpetradas pelo Estado pode ter servido de alguma forma para a manutenção de uma cultura de violência contra as mulheres. Especificamente relacionada à manutenção de uma cultura autoritária e violadora de direitos humanos, insensível às questões de gênero, retomamos uma declaração realizada pelo então Deputado Federal Jair Bolsonaro. O parlamentar prestou homenagem ao coronel Carlos Alberto Brilhante Ustra, por seus atos de tortura contra Dilma Rousseff ${ }^{1}$. Durante a ditadura civil-militar brasileira, a ex-Presidenta atuara como opositora ao regime, o que motivou sua perseguição política, detenção e sessões de tortura. Essa homenagem foi proferida na Câmara dos Deputados em votação a respeito da abertura de processo de Impeachment contra a Presidenta da República, no ano de 2016 (Borba e Wentzel, 2016).

Também em 2016, uma candidata a vereadora pela cidade de São Paulo, afirmou ter ouvido que "merecia ser estuprada e torturada", disseram a ela que o coronel [Carlos Brilhante] Ustra "torturou quem mereceu, como as feministas" (Joffily, 2016, p. 166) ${ }^{2}$. Compreende-se então, que há a necessidade de se prosseguir com estudos que discutam as violações perpetradas por agentes da ditadura, em uma associação constante da tortura como castigo a uma atuação das mulheres, vistas como subversivas.

Para tanto, busca-se analisar mais detidamente como as graves violações de direitos humanos baseadas em gênero são tratadas nos pareceres dos conselheiros da Comissão de Anistia Política, do Ministério da Justiça ${ }^{3}$, se e como as mesmas violações, ou com similaridades, são abordadas na

\footnotetext{
${ }^{1}$ Trata-se de reconhecido membro das forças armadas, coronel do Exército, que atuou expressivamente durante a ditadura civil-militar, tendo chefiado o DOI-CODI do II Exército, em São Paulo/SP. Em 2008, o Judiciário brasileiro reconheceu Ustra como torturador, em âmbito cível (Comissão Nacional da Verdade, 2014).

${ }^{2}$ Mônica Bergamo, 'Feministas merecem tortura', ouve candidata à Câmara Municipal em SP. Folha de S.Paulo, 2 out. 2016. Disponível em: http://www1.folha.uol.com.br/colunas/monicabergamo/2016/10/1818623-feministas-merecemtortura-ouve-candidata-a-camara-municipal-em-sp.shtml. Acesso em: 02 set. 2017.

${ }^{3}$ Importante ressaltar que durante a escrita desse artigo, e consequente processo de tramitação para a publicação, houve algumas alterações em relação à Comissão de Anistia, que sai do Ministério da Justiça e passa a ser subordinada ao Ministério Mulher, Família e Direitos Humanos. Essa alteração e as seguintes que se processaram impactaram muito na atuação da CA, impactos que serão analisados em pesquisa futura.
} 
narrativa ficcional de Eltit. Objetiva-se, então, perceber aproximações entre como foram tratadas as violações baseadas em gênero nos pareceres e na obra citada da chilena Diamela Eltit.

\section{Constitucionalismo, teoria crítica e a perspectiva feminista, diálogos necessários}

Inicialmente, em uma tentativa de localizar o presente artigo epistemologicamente, tentaremos retomar um pouco da perspectiva das teorias críticas nas quais pretende sua inserção. A escolha por essa perspectiva relaciona-se à necessidade de se afastar daquela compreensão em que se afirmava 0 pesquisador como um eu universal, neutro, objetivo, a-histórico, ou mesmo da ciência como autônoma, imparcial (Horkheimer, 1975, p. 37, 55). A razão de se buscar esse afastamento vem da impossibilidade da existência desse eu universal proclamado pelo positivismo científico, "o mito da ciência, do saber absoluto, como se fôssemos capazes de produzir algo eterno, imutável, perfeito" (Carvalho Netto, 2012, p. 28). O que se afirma aqui é que essa promessa/pretensão de universalidade, de generalização falha e acaba por entregar um resultado parcial, que pelo seu locus privilegiado, se pretende não marcado, entendendo-se a si mesmo como generalizante, ou seja, uma determinada perspectiva, parcial e localizada se apresenta como universal. São essas algumas das considerações que pretendem localizar a presente proposta na busca pela superação "do mito da razão moderna, que seria capaz de revelar verdades eternas, imutáveis, a-históricas, bem como o reconhecimento dos altos custos pagos pela crença nesse mito" (Carvalho Netto, 2012, p. 25).

Essa pretensa objetividade e racionalidade acaba por excluir quaisquer experiências que não sejam desse eu universal, que é, em sua essência, uma tentativa de universalização de um conhecimento parcial, do homem branco, heterossexual (Haraway, 2009, p. 18). Assim, pretende-se contribuir, partindo de uma perspectiva feminista, que significaria afirmar-se exatamente nesses saberes localizados, responsabilizáveis. A busca por uma perspectiva parcial relaciona-se à possibilidade de ser responsabilizável tanto pelas suas promessas quanto por seus resultados (Haraway, 2009, p. 21). Dessa forma, parte-se da compreensão da parcialidade da ciência como pressuposto, contrastando-se à existência de uma imparcialidade a ser alcançada pelo pesquisador, entendendo que esse não tem a "função de um indivíduo isolado nem a de uma generalidade de indivíduos", mas insere-se em uma rede de relacionamentos (Horkheimer, 1975, p. 46). Pretende-se aqui "uma abordagem interdisciplinar, histórica, crítico-reconstrutiva e antidualista, que se remete às amplas tarefas de uma teoria crítica da sociedade, da modernidade e da razão" (Cattoni de Oliveira, 2017, p. 101).

Seguindo nesse caminho, pretende-se ainda avançar juntamente com as epistemologias feministas, através de Donna Haraway, para quem a pesquisa deve ser além de localizada, corporificada. Ao contrário de uma tentativa de silenciamento de todas as outras perspectivas, ou opressões, como raça, classe e aquelas relacionadas a diversidade sexual, o que se pretende é não incorrer em uma leitura universalizante, insensível às particularidades das pautas e mesmo das vivências. Como Haraway (2009, p. 18), objetiva-se deixar claro que se trata de uma pesquisa localizada e corporificada, a partir de uma perspectiva específica e parcial (Haraway, 2009, p. 22, 26). Perspectiva essa que por ser parcial pode contribuir para a construção de uma ciência mais completa, por somar-se a outras perspectivas diversas.

A presente discussão aqui desenvolvida insere-se em uma compreensão mais ampla a respeito do constitucionalismo, de seu potencial transformador, através do entendimento do projeto 
constituinte fundado no Brasil em 1988. Processo que teve como um de seus resultados uma Constituição promulgada fruto de um dos momentos mais marcantes da democracia brasileira, que "articula memória e projeto, experiência e expectativa" (Cattoni de Oliveira, 2010, p. 201). Especificamente, parte desse projeto constituinte será analisado a partir do artigo $8^{\circ}$ do Ato das Disposições Transitórias - $\mathrm{ADCT}^{4}$, sua regulamentação e efetivação. A intenção aqui não se dá apenas a respeito desse artigo, mas, compreendendo com Menelick de Carvalho, que a Constituição constitui uma comunidade fundada sobre princípios (Carvalho Netto, 2012, p. 158). Essa compreensão nos guia por uma análise que tem como pressuposto o compromisso com o Estado Democrático de Direito. Apresenta-se, então, uma tentativa de reconstrução de uma história institucional "que reflita um processo de aprendizado social, com o direito e com a política, em longo prazo" (Cattoni de Oliveira, 2017, p. 110), em uma análise de "como nos posicionamos responsavelmente, aqui e agora, em relação às gerações passadas e futuras" (Cattoni de Oliveira, 2017, p. 111). Nessa perspectiva, compreendendo "a transição política como um processo constituinte democrático a longo prazo" (Cattoni de Oliveira, 2010, p. 208).

Para melhor fundamentação da discussão que aqui se delineia, as críticas feministas serão mais detalhadamente mobilizadas no próximo tópico.

\section{Feminismos e Resistências}

As violações baseadas em gênero perpetradas durante a ditadura civil-militar brasileira demonstram uma opressão de gênero contra as mulheres, opressão essa que ressoa também em práticas cotidianas mesmo após o fim do regime autoritário. Para os fins propostos e em coerência com a discussão a ser desenvolvida, entendemos gênero como

um campo de diferença estruturada e estruturante, no qual as tonalidades de localização extrema, do corpo intimamente pessoal e individualizado, vibram no mesmo campo com as emissões globais de alta tensão. A corporificação feminista, assim, não trata da posição fixa num corpo reificado, fêmeo ou outro, mas sim de nódulos em campos, inflexões em orientações e responsabilidade pela diferença nos campos de significado material - semiótico. Corporificação é prótese significante; a objetividade não pode ter a ver com a visão fixa quando o tema de que trata é a história do mundo (Haraway, 2009, p. 29-30).

Norteadoras principais da presente abordagem, as teorias feministas são várias e diversas entre si. Para Claire Dalton, uma epistemologia feminista parte do pressuposto de que aquilo até então apresentado como universal, como verdade serviu para silenciar e obscurecer a perspectiva e a vivência das mulheres (Dalton, 2013, p. 6). A autora compreende que ser feminista significa compreender a sociedade contemporânea a partir da perspectiva de que as mulheres são e têm sido

\footnotetext{
4 “Art. $8^{\circ}$ É concedida anistia aos que, no período de 18 de setembro de 1946 até a data da promulgação da Constituição, foram atingidos, em decorrência de motivação exclusivamente política, por atos de exceção, institucionais ou complementares, aos que foram abrangidos pelo Decreto Legislativo $\mathrm{n}^{\mathrm{o}} 18$, de 15 de dezembro de 1961, e aos atingidos pelo Decreto-Lei $\mathrm{n}^{\circ} 864$, de 12 de setembro de 1969, asseguradas as promoções, na inatividade, ao cargo, emprego, posto ou graduação a que teriam direito se estivessem em serviço ativo, obedecidos os prazos de permanência em atividade previstos nas leis e regulamentos vigentes, respeitadas as características e peculiaridades das carreiras dos servidores públicos civis e militares e observados os respectivos regimes jurídicos".
} 
subordinadas para e pelos homens, e que o fim dessa subordinação significaria uma melhoria na vida das mulheres e possivelmente na vida dos homens também. É nessa chave de leitura que o feminismo abarca uma variedade de pesquisas e atuações comprometidas a descrever, compreender e contribuir para o fim dessa subordinação (Dalton, 2013, p. 6). Inicialmente, retomaremos a discussão através de obras selecionadas para representar aspectos marcantes ressaltados pela compreensão até então hegemônica e linear do desenvolvimento do feminismo em ondas ${ }^{5}$.

Essa perspectiva começa a se desenhar no contexto dos movimentos por direitos civis, incluídos nesses, os movimentos por direitos da mulher, nos Estados Unidos, que ocorreram nas décadas de 1960 e 1970. Assim, compreendeu-se naquele momento, que a primeira onda do feminismo constituía-se a partir da organização das mulheres em prol do sufrágio universal. Um movimento que ocorreu no século XIX e início do século XX, em países como França, Reino Unido, Canadá, Estados Unidos, Brasil, tendo como teóricas Christine de Pizan, Marie Gouze (Olympe de Gouges), Mary Wollstonecraft ${ }^{6}$.

O desenvolvimento dessa compreensão do feminismo em ondas surge em publicações da década de 1960, que tem como marco inicial da primeira onda a primeira Convenção por Direitos das Mulheres (The Seneca Falls Convention), que ocorreu em julho de 1848, nos Estados Unidos. E como marco final, a conquista do sufrágio feminino, através de Emenda Constitucional, em 1920. Mesmo que inicialmente não se considerasse o ativismo pelo sufrágio universal do século anterior como predecessor do movimento pelos direitos das mulheres das décadas de 1960/1970, é nesse momento que se inicia o delineamento do que se compreendeu como a segunda onda do feminismo (Henry, 2004, p. 57). O termo segunda onda foi primeiramente cunhado por Marsha Weinman Lear, em artigo publicado na New York Times Magazine, em março de 1968 (Henry, 2004, p. 58). A adoção da metáfora de ondas para o feminismo, uma inicial e outra em desenvolvimento traz em seu léxico a caracterização de que se tratava de um movimento político histórico, legítimo, em construção, mas que também apresentava demandas novas, para além do já conquistado direito ao sufrágio feminino. Mesmo sentido em que se anuncia a terceira onda do feminismo, na década de 1990 (Henry, 2004, p. 58). Essa fase do feminismo

concentra-se na análise das diferenças, da alteridade, da diversidade e da produção discursiva da subjetividade. Com isso, desloca-se o campo do estudo sobre as mulheres e sobre os sexos para o estudo das relações de gênero. Neste sentido é que algumas posições, ainda que heterogêneas, distinguem os Estudos Feministas - cujo foco se dá principalmente em relação ao estudo das e pelas mulheres, mantidas as estreitas relações entre teoria e política-militância feminista - dos Estudos de Gênero, cujos pressupostos abarcam a compreensão do gênero enquanto categoria sempre relacional (Scott, 1986). O desafio nesta fase do feminismo é pensar, simultaneamente, a igualdade e a diferença na constituição das subjetividades masculina e feminina (Narvaz e Koller, 2006, p. 649).

\footnotetext{
${ }^{5}$ A escolha por apresentar o desenvolvimento do feminismo em ondas se deu em razão de ser uma das perspectivas mais difundidas, e mesmo para criticá-la, é necessário retomá-la. Não se ignoram as críticas a essa perspectiva no que ela mesma pode ser silenciadora de outros feminismos e outras formas de opressão. A compreensão da autora em relação a essas críticas será desenvolvida na dissertação.

${ }^{6}$ Os termos primeira e segunda onda do feminismo só são utilizados a partir da década de 1960, cunhados por Marsha Weinman Lear (Henry, 2004, p. 58).
} 
Essa narrativa construída pelas feministas radicais, de nascimento do feminismo na Convenção no Seneca Falls, sua morte após a Emenda Constitucional de 1920, nos Estados Unidos, e seu renascimento em 1968 silenciou muito da história do próprio feminismo estadunidense, além dos feminismos diversos daquele. Anteriormente à Convenção citada, várias mulheres se colocaram em luta por seus direitos, por igualdade, liberdade, educação. Para citar uma, ainda parte de um feminismo branco hegemônico, em 1792, Mary Wollstonecraft publicava Reivindicação dos Direitos da Mulher, em que defendia a igualdade entre os sexos (Wollstonecraft, 2016, p. 205). Ainda anteriormente à Convenção, em 1832, a brasileira Nísia Floresta Brasileira Augusta publicava Direitos das mulheres e injustiça dos homens, primeiro livro brasileiro a tratar do direito ao trabalho e à educação das mulheres (Duarte, 2003, p. 153).

Esse feminismo radical autoproclamado de segunda onda pretendeu se afastar do feminismo liberal estadunidense, contemporâneo àquele, preferindo afiliar-se ao que desenvolvia Simone de Beauvoir, na França. Segundo Astrid Henry, esse alinhamento da pensadora francesa ao intelectualismo francês a afastava daquilo que as feministas radicais também pretendiam abandonar, ao se contraporem ao feminismo liberal de Friedan, "o mundo desinteressante da dona de casa" (Henry, 2004, p. 69, tradução livre).

Friedan representava - tanto figurativa quanto literalmente - a imagem da mãe real demais para essas feministas jovens para que desempenhasse satisfatoriamente um papel de mentoria em seu movimento florescente. Beauvoir, por sua vez, representava o tipo de mulher emancipada que muitas das feministas radicais queriam emular. Uma escritora e intelectual, que era contra o papel reprodutivo da mulher e escolheu não fazer parte da instituição do casamento, Beauvoir fez muitas escolhas de vida que as feministas radicais estavam começando a considerar para elas mesmas. Para feministas radicais como Firestone, Beauvoir simbolizava a antítese de Friedan e do mundo doméstico feminino que ela representava (Henry, 2004, p. 70) ${ }^{7}$.

Essa narrativa construída entre a primeira e a segunda onda do feminismo, de forma hegemônica e centralizada no movimento feminista estadunidense fora criticada por representar um movimento essencialmente branco, de classe média e heterossexual. Apresentava como fundamento da crítica feminista uma unidade ideal do sujeito mulher que se torna mais fortemente questionada com o desenvolvimento da terceira onda do feminismo estadunidense. Ainda que essa narrativa tenha se construído através do reconhecimento de que a luta abolicionista levou ao movimento pelo sufrágio feminino e a luta dos movimentos antirracistas pelos direitos civis ao feminismo radical, não reconheceu a interseccionalidade entre raça e gênero. A consequência nefasta de entender um movimento como focado exclusivamente na opressão da raça e o outro exclusivamente em opressão

\footnotetext{
${ }^{7}$ No original: Friedan was - in both a literal as well as figurative sense - too much of real mother figure to these Young feminists for her to successfully play the role of mentor to their burgeoning movement. Beauvoir, on the other hand, represented the kind of emancipated woman many radical feminists wanted to emulate. An intellectual and writer, someone who was virtually against the reprodutive role of women and had chosen not to participate in the institution of marriage, Beauvoir had made many of life choices that radical feminists were just beginning to consider for themselves. To radical feminists such as Firestone, Beauvoir symbolized the antithesis of Friedan and the domestic female world she represented (Henry, 2004, p. 70).
} 
de gênero é o desaparecimento da vivência e militância das mulheres negras (Henry, 2004, p. 76). Essa retórica difundida e analisada nos últimos trinta anos por feministas não acompanhou uma análise criteriosa das diferenças entre as mulheres, como raça e classe. $\mathrm{O}$ feminismo negro tem trazido à discussão essa interseccionalidade entre raça, classe e gênero (Davis, 2016; Ribeiro, 2017).

A discussão a respeito da sexualidade, outro vértice do sistema de opressão a ser tratado pelo feminismo, começou a ser desenvolvida ainda nas décadas de 1960 e 1970 pelas primeiras autoras auto identificadas com a segunda onda. São temas caros às feministas radicais o orgasmo clitoriano, homossexualidade lésbica e bissexualidade, monogamia, além dos temas discutidos já na primeira onda, casamento, trabalho doméstico e a "natureza" da mulher (Henry, 2004, p. 82) ${ }^{8}$.

Após esse breve percurso através do pensamento feminista, abordaremos mais especificamente essa perspectiva relacionada a pesquisas que se inserem no campo do direito. Segundo Dalton, o pensamento feminista legal é aquele que se volta tanto para a pesquisa quanto para a atuação relacionadas ao sistema jurídico, tanto às leis, discursos, instituições através das quais o direito pode ser subvertido, incluindo-se também as instituições de ensino jurídico, possibilitadoras e, em determinados contextos, responsáveis pela preservação de um pensamento jurídico enviesado (Dalton, 2013, p. 2).

A compreensão do feminismo adotada permite a consideração de duas obrigações: não se apresentar como um único feminismo, nem se pretender hegemônico. Positivamente, pois não se pretende com as teorias feministas substituir o pensamento hegemônico por um que também se pretenda universal e absoluto, a ideia aqui retoma a produção científica como localizada, corporificada, e parcial, perspectiva de Haraway.

Não queremos uma teoria de poderes inocentes para representar o mundo, na qual
linguagens e corpos submerjam no êxtase da simbiose orgânica. Tampouco
queremos teorizar o mundo, e muito menos agir nele, em termos de Sistemas
Globais, mas precisamos de uma rede de conexões para a Terra, incluída a
capacidade parcial de traduzir conhecimentos entre comunidades muito diferentes -
e diferenciadas em termos de poder. Precisamos do poder das teorias críticas
modernas sobre como significados e corpos são construídos, não para negar
significados e corpos, mas para viver em significados e corpos que tenham a
possibilidade de um futuro (Haraway, 2009, p. 16).

A segunda obrigação se dá pelo reconhecimento de que nenhuma narrativa ou teoria feminista pode falar em uma única voz por todas as mulheres (Dalton, 2013, p. 7). A análise aqui proposta direciona-se a políticas públicas de reparação lidas a partir da lente de compreensão da perspectiva feminista. Por se relacionar à institucionalidade do Estado e por inserir-se no campo da pesquisa jurídica, importante ressaltar que não se parte de uma visão romantizada de que o direito colocado frente a argumentos sólidos o suficiente será automaticamente modificado, abandonando as formas de opressão até então permitidas e garantidas por ele. Um dos aspectos principais reconhecidos pelo feminismo é que a opressão é relacional, reconhece "o poder do direito como uma realidade política [...]. Reconhece o fórum legal como um locus de poder. Não avança em uma crítica aos direitos per se mas à sua forma e conteúdo como masculinos, portanto excludente, limitado e limitador"

\footnotetext{
${ }^{8}$ Conferir Koedt (1973).
} 
(Mackinnon, 1989, p. XIII). Um dos pressupostos guia da presente pesquisa relaciona-se à compreensão de que

\begin{abstract}
"mulheres" e outras minorias são constructos sociais, as mulheres que as vidas são conformadas por essa construção e outras interseccionalidades existem de fato. Existem subordinadas aos homens: pobres, mais que os homens; física e sexualmente abusadas mais que os homens; têm menores salários quando comparadas aos homens; menos promovidas em seus empregos; dupla jornada de trabalho mais que os homens; responsáveis pela criação de crianças mais que o homem; apresenta diferenças na performance profissional quando comparadas a seu par masculino tanto na academia quanto fora dela; explorada, difamada e estereotipada na imagem da cultura popular mais que homens (Dalton, 2013, p. 10-11).
\end{abstract}

Ao contextualizar essa discussão sobre o movimento feminista no Brasil durante o regime civilmilitar, segundo Amelinha Teles $(2017$, p. 63), as mulheres foram as primeiras a aparecerem, a "entrarem em cena", através da busca por seus companheiros, amigos e familiares, que estavam desaparecidos, vítimas da perseguição política. Outras iniciaram sua participação na resistência ao regime através de organizações clandestinas, em uma atuação lado a lado com os homens. Conforme Sônia Alvarez, o feminismo no Brasil enraizou-se profundamente na oposição política ao regime civil-militar (Alvarez, 2014, p. 21). Em um evento marcante, mais de 100 mil pessoas se reuniram no Rio de Janeiro para protestar a morte de um adolescente de 16 anos de idade, o Edson Luís, assassinado pelo regime militar. Essa manifestação, que ocorreu em momento de seu funeral, foi a razão propulsora de várias outras manifestações, e alianças, das quais surgiu a união de mães pela defesa de seus filhos, com a criação da União Brasileira de Mães (Teles, 2017, p. 65).

Com o contato cada vez maior de grupos femininos com feministas, temas como aborto, sexualidade e orientações sexuais, apesar de polêmicos naquele momento, começaram a aparecer nesses encontros. Porém, dirigentes políticos e religiosos tentavam impedir que feministas abordassem esses temas, e outros, como violência sexual e doméstica. $O$ argumento dessa deslegitimação da pauta feminista apresentava-se sempre acompanhado da frequente afirmação de que elas dividiriam o movimento operário, enfraqueceriam a luta por transformações sociais. Teles (2017, p. 86-87) afirma que a palavra "estupro" era utilizada apenas em ambientes policiais. Mas o feminismo fortalecia-se no contexto internacional, através da luta por direitos civis e da revolução sexual norte-americana, tanto que a Organização das Nações Unidas - ONU, declarou a década de 1970 a Década da Mulher9.

Essa declaração incentivou ainda mais o feminismo crescente em terras brasileiras, dando início à retomada das atividades públicas relacionadas ao dia 08 de março, dia internacional da mulher, para celebrar e relembrar o significado da data.

Em 1976, ocorre a primeira comemoração pública dessa data após 1964. No auditório do Masp (Museu de Arte de São Paulo) reuniram-se por volta de 300 pessoas, convidadas pelo jornal Brasil Mulher e pelo Movimento Feminino pela

\footnotetext{
${ }^{9}$ Outro fator internacional que influenciou o feminismo no Brasil foi o exílio de mulheres militantes e o envolvimento das mesmas com o movimento feminista que se fortalecia e expandia. Um dos exemplos é o Círculo de Mulheres Brasileiras em Paris, fundado em 1976 (Camargo, 2010, p. 74).
} 
Anistia. [...] Uma representante das mulheres negras, homossexual, pediu a palavra para denunciar a discriminação que sofrem os homossexuais e principalmente a lésbica. Fato que causou espanto e mal-estar, pois ninguém naquela época falava sobre a homossexualidade, muito menos em público. Além disso, as mulheres que iniciaram a luta feminista eram, como às vezes o são até hoje, chamadas de lésbicas ou 'sapatão' (o termo mais popular). Por isso ninguém comentou o que falou a lésbica, para que o assunto caísse no esquecimento. Aliás, a fala dessa negra incomodou mais que a presença dos policiais que procuravam intimidar as manifestantes (Teles, 2017, p. 106-107).

A citação acima reflete como que dentro da militância política havia uma rejeição de pautas ainda minoritárias, como as relacionadas à raça e à sexualidade. O movimento das feministas negras, durante esse período, resultou em organizações auto proclamadas autônomas em relação ao feminismo "branco", e do movimento negro misto, refletindo sobre a sua diversidade em relação aos demais (Alvarez, 2014, p. 24-25). O clima de efervescência feminista não modificou a atuação dos líderes partidários, segundo os quais as militantes do partido não deveriam discutir pautas como sexualidade, aborto, o direito a decidir sobre o próprio corpo, negando também as pautas sobre violência sexual e doméstica. Interessante salientar que a oposição ao regime autoritário não se fez por um grupo homogêneo com pautas exatamente iguais, houve a adoção da luta armada por parte da esquerda, assim como uma oposição feita por familiares antes não relacionados à atuação política, e várias outras divergências entre os movimentos de oposição.

Mesmo com toda essa divergência, o posicionamento majoritário dos dirigentes dos movimentos de oposição rechaçavam a urgência da pauta feminista. A argumentação girava em torno da possível divisão do movimento operário (Teles, 2017, p. 127). A questão da orientação sexual e a perseguição em razão da mesma era constantemente rechaçada, até mesmo pelo próprio movimento de mulheres, como pode ser observado na citação abaixo, em discussão a respeito do III Congresso da Mulher Paulista:

As militantes do MR-8 [Movimento Revolucionário 8 de Outubro] falavam aos jornais que não permitiriam a entrada de lésbicas no movimento. Uma das militantes, Márcia Campos, declarou à Folha de São Paulo (11/2/1981) que a "lésbica nega a sua própria condição de mulher, e não pode fazer parte de um movimento feminino" (Teles, 2017, p. 131).

Apesar dessa dificuldade em perceber como as pautas lésbicas se colocavam frontalmente contra o autoritarismo, de uma matriz heteronormativa de regulação dos corpos, esses grupos representaram um importante avanço na inserção dessa discussão na militância de esquerda. Um dos métodos de difusão dessas questões foi o lançamento do jornal Chana com Chana, pelo Grupo de Ação Lésbico-Feminista, ampliando os horizontes sobre a sexualidade feminina. Nesse momento, uma preocupação passa a ser discutida por esses grupos, a preocupação relativa ao risco de contaminação pelo vírus HIV/Aids, em razão da epidemia da doença que se alastra durante a década de 1980. Outros modos de atuação e novas perspectivas têm se delineado no contexto brasileiro, como o transfeminismo, o transgênero, o pós-gênero, queer, dentre outros (Alvarez, 2014, p. 44). 


\section{Livro dos Votos CA/MJ e Jamais o Fogo Nunca - tentativas de aproximação}

Esse tópico será dividido em dois momentos, inicialmente, trataremos de dois votos selecionados do livro dos votos, acima mencionado. Para tanto, é necessário fazer uma breve contextualização do mesmo, por resultar de parte das políticas públicas desenhadas e implementadas pelo Estado brasileiro. Esse programa de reparação faz parte de um conjunto de iniciativas do Estado a fim de conduzir adequadamente a transição política do regime autoritário anterior para a democracia, e lidar com as violações perpetradas no regime anterior. E, em um segundo momento, traremos trechos do monólogo chileno, que apresentam a possibilidade de aproximação, especificamente no que se relaciona à abordagem de violações baseadas em gênero, reconhecidas pela literatura especializada.

De acordo com a normativa do direito internacional dos direitos humanos, para que essa transição caminhe em direção a uma democracia consolidada, quatro mecanismos tradicionais precisam ser implementados. Esses quatro mecanismos tradicionais fazem parte do campo de atuação de pesquisadores, profissionais e ativistas conhecido como justiça de transição e são o direito à memória e à verdade, reparações, responsabilizações e reformas institucionais. O termo justiça transicional foi sendo construído no âmbito do direito internacional dos direitos humanos, reconhecendo-se a importância de que seus quatro mecanismos tradicionais sejam implementados holisticamente, colaborando para a efetivação dos mesmos, a fim de que se construa e estabeleça um regime democrático (Meyer, 2012, p. 253). Trata-se de conceito em construção que se apoia em dois objetivos normativos centrais, sendo o primeiro deles alcançar a justiça para as vítimas das graves violações de direitos humanos perpetradas durante um passado autoritário ou de conflito armado, e o segundo a busca por uma ordem mais justa e democrática (Teitel, 2002, p. 11; Arthur, 2009, p. 357).

$O$ contexto latino-americano de rupturas institucionais vivenciadas durante a segunda metade do século XX, e suas posteriores transições democráticas ofereceram aos estudiosos da justiça de transição um campo fértil ${ }^{10}$. Cada país desenvolveu uma experiência particular no campo da implementação dos mecanismos da justiça transicional. A Argentina, por exemplo, tem sido bem sucedida em empenhar responsabilizações criminais individuais dos perpetradores das graves violações de direitos humanos, revogando as leis de "Ponto Final" e "Obediência Devida", que foram declaradas inconstitucionais pela Corte Suprema, também reconheceu a imprescritibilidade de crimes contra a humanidade (Meyer, 2012, p. 247). Além das responsabilizações, a busca pela verdade teve início logo após o fim do regime autoritário argentino, com a criação da Comissão Nacional sobre Desaparecimento de Pessoas - CONADEP. No Chile também houve responsabilizações criminais individuais, ainda que a lei de anistia continue no sistema jurídico, e a busca pela verdade foi realizada através da criação da “Comisión Nacional sobre Prisión Política y Tortura”. Importante ressaltar que as Comissões da Verdade da Argentina, do Chile e do Brasil, trataram questões relativas às violações baseadas em gênero, no que concerne especificamente a violência sexual:

Os relatórios conhecidos como "Nunca más", produzidos pelas comissões da verdade oficiais, da Argentina e do Chile, ou por organizações da sociedade civil, no

\footnotetext{
${ }^{10}$ Nesse sentido, sem esgotar as referências, citam-se Meyer (2012) e Pereira (2010). Salienta-se a criação da Rede LatinoAmericana de Justiça de Transição (RLAJT), em 2013, que atualmente conta com 17 instituições, representantes de 9 países da América Latina. Disponibilizam-se várias publicações em seu sítio eletrônico, incluindo relatórios sobre a implementação de mecanismos de justiça transicional na América Latina. Disponível em: http://rlajt.com/biblioteca/publicacoes/. Acesso em: 02 set. 2017.
} 
Brasil e Uruguai, referiram-se às violências sexuais sofridas durantes as ditaduras, sem, contudo, atribuir-lhe uma dimensão à parte ou o espaço que seu caráter reiterado exigiria. Além disso, houve evidente subnotificação. No relatório brasileiro, por exemplo, que abarcou tanto as vítimas fatais (mortos e desaparecidos), como as torturas sofridas em instalações do Estado, as violências sexuais correspondem a $1 \%$ das denúncias femininas. O relatório da Comisión Nacional Sobre Prisión Política y Tortura do Chile, conhecido como Informe Valech, entregue em dezembro de 2004, dá sinais de uma mudança em curso nas reflexões que apresenta sobre o crime sexual (Joffily, 2016, p. 169).

Países como Guatemala, Colômbia, África do Sul e Timor Leste têm pensado, discutido e desenhado formas de implementação dos mecanismos da justiça transicional para se adequarem aos seus contextos específicos ${ }^{11}$.

É necessário deixar claro, contudo, que não se ignora que algumas formas de violência a que as mulheres estão sujeitas são similares àquelas que homens são submetidos, contudo, as atingem de maneira diferente, relacionando-se a especificidades das estruturas sociais em que se encontram.

Mais importante, a reparação da experiência das mulheres em conflitos mostra que mesmo quando mulheres são submetidas as mesmas violações que os homens, seu status socioeconômico e legal pré-existentes, bem como o significado cultural ao redor da construção do masculino e do feminino em sociedades patriarcais podem implicar que os danos subsequentes para homens e mulheres não são os mesmos. Demonstram também múltiplos caminhos em que a violência afeta famílias e comunidades e então as formas em que a violência perpetrada contra homens também vitimiza mulheres e a estrutura diária de suas vidas ${ }^{12}$ (Rubio-Marín, 2006, p. 24, tradução livre).

Em momentos de transição entre regimes, em que se tem uma reconstrução ou retorno a um regime democrático, pode-se perceber através do acervo histórico, comparativo e interpretativo apresentado pela justiça de transição e através da implementação de seus mecanismos, o compromisso daquele Estado com a justiça e com o Estado Democrático de Direito (Meyer, 2012, p. 252) ${ }^{13}$.

Assim, é no contexto da justiça de transição que formas de superar as injustiças passadas permitiram o surgimento de questionamentos relacionando a desigualdade de gênero à justiça transicional. Em períodos de ruptura institucional, as violações perpetradas contra as mulheres têm um caráter político, baseado na relação de poder e hierarquia entre gêneros. Nesses momentos, reafirma-se o lugar da mulher, de acordo com seu papel de gênero, e na divisão entre público/privado, que relega à mulher o espaço doméstico, em que se realiza o trabalho reprodutivo, de cuidados e criação dos filhos, baseado na divisão sexual do trabalho:

\footnotetext{
${ }^{11}$ Para uma discussão a esse respeito, conferir Rubio-Marín (2006).

${ }^{12}$ No original: More importantly, the accounts of women's experiences in conflict show that, even when women are subject to the same violations as men, their pre-existing socioeconomic and legal status, as well as the cultural meanings around the construction of the male and the female in patriarchal societies, may imply that the ensuing harms for men and women are not the same. They also demonstrate the manifold ways in which violence affects families and communities and thus the forms in which violence perpetrated against men also victimizes women and the structures they rely upon in their daily lives (Rubio-Marín, 2006, p. 24).

${ }^{13}$ Para a análise de pesquisas transdisciplinares, conferir Franco (2015) e Gianordoli-Nascimento et al (2012).
} 
As mulheres politicamente ativas são punidas duplamente: primeiro porque são consideradas inimigas de Estado; e segundo, porque elas quebram normas de gênero, tendo se "atrevido" a intervir no domínio público, um domínio tradicionalmente masculino (Bailey e Paz, 2006, p. 97, tradução livre) ${ }^{14}$.

Assim, como parte das iniciativas para a transição e para o tratamento das graves violações cometidas por agentes do Estado, a publicação do livro de votos, aqui parcialmente discutido, é resultado da atuação da Comissão de Anistia/MJ. São ao todo 115 votos reunidos, selecionados para abarcar pareceres desde o ano 2001 até 2012, cerca de 11 anos de atuação e foram escolhidos de forma a constar no livro representantes de todos os grupos que se colocaram em oposição ao regime, "os comunistas, os religiosos, os estudantes, as mulheres..." (Brasil, 2013, p. 18). Desses 115 pareceres, 28 (vinte e oito) referem-se a pedidos de anistiandas, militantes perseguidas pelo Estado durante o regime civil-militar. São dois os votos a serem aqui discutidos, relativos aos requerimentos n ${ }^{\mathrm{o}}$ 2002.01.09368 (Relator: Conselheiro Egmar José de Oliveira), e no 2006.01.53412 (Relatora: Conselheira Sueli Aparecida Bellato), ambos referentes a mulheres que se opuseram contra o regime autoritário.

O primeiro requerimento refere-se ao pedido de anistia política de Helena Serra Azul Monteiro, estudante de medicina na década de 1960, na Universidade Federal do Ceará, que iniciou sua militância no movimento estudantil, tendo se filiado ao Partido Comunista do Brasil. Em outubro de 1969, ela e seu marido foram presos no Município de São Francisco do Sul, Pernambuco. Parte das violações baseadas em gênero perpetradas contra as mulheres atingem, ou buscam atingir, seus direitos reprodutivos, uma vez que o ato de ter filhos é muito mais associado às mulheres que aos homens. Helena estava grávida de dois meses quando foi presa. Segundo o relatório constante no parecer, ela foi mantida incomunicável por 40 (quarenta) dias, nos quais sofreu ameaças de aborto, e de "sevícias" (Brasil, 2013, p. 216), tendo também presenciado torturas perpetradas contra seu marido. Permanecera em cárcere por dois anos, em consequência do que teve seu filho nessas condições. A ela foi permitido ficar com o filho Manoel por oito meses, mas depois foi obrigada a se separar dele. Em 1972, foi novamente presa e torturada, tendo sido mantida por duas semanas incomunicável. Esse relato sobre o tempo da prisão, torturas e a relação com a maternidade consta no relatório do parecer, em que o pedido formulado pela anistianda, juntamente com a documentação colacionada são analisados e relatoriados, resumidamente. Assim, o que nos interessa aqui é discutir quais violações o relator ressalta, fazendo constar no relatório, bem como na segunda parte do parecer, no voto. Segue um trecho elucidativo:

Abaixo da escala zoológica dos irracionais porque não respeitavam sequer mulheres
grávidas, como o caso da nossa Anistianda, que mesmo estando grávida de dois
meses de seu filho Manoel, foi brutalmente torturada física e psicologicamente com
consequências trágicas para as vidas futuras de ambos. Assim, é inegável a
perseguição política por ela sofrida, nas diferentes formas, decorrentes da sua

\footnotetext{
${ }^{14}$ No original: Politically active women were doubly punished: first, because they were considered enemies of the state; and second, because they broke gender norms by having "dared" to intervene in the political realm, a traditionally "male" domain (Bailey e Paz, 2006, p. 97).
} 
indelével participação na luta contra a ditadura Militar, como se vê na farta documentação acostada nos autos (Brasil, 2013, p. 217).

Outro resultado da perseguição política comum às experiências dos dissidentes políticos é a obrigatoriedade de uma vida clandestina. Nesse parecer em análise, o relator ressalta essa experiência:

E mais. Foi compelida a viver clandestinamente no seu próprio país, até ser presa e barbaramente torturada. Indiciada e processada com base na famigerada lei de Segurança Nacional, foi condenada a uma pena de 05 (cinco) anos de reclusão, pena esta reduzida para 02 (dois) anos, conforme decisão do Superior Tribunal Militar (Brasil, 2013, p. 217).

O sofrimento provocado pela perseguição política às mulheres enquanto mães é tema recorrente também no segundo parecer analisado, mas não apenas, representam a experiência de várias mulheres que foram perseguidas políticas e estiveram sob a custódia do Estado (Gianordoli-Nascimento, 2012, p. 298-299). Passando para a análise do segundo parecer, trata-se do requerimento de anistia política da militante Eliana Belline Rolemberg. Ela formou-se em Ciências Sociais pela Pontifica Universidade Católica de São Paulo - PUC/SP, em 1966, tendo sido admitida como funcionária do Governo do Estado de Sergipe em 1968. Foi presa juntamente com o coordenador do projeto em que trabalhava por portar material subversivo, pela OBAN, tendo permanecido vinte dias sob custódia. Após esses dias, foi transferida para DEOPS, e depois para a Prisão Tiradentes. As torturas relatadas pela conselheira relatora não foram aquelas tradicionalmente reconhecidas como violações baseadas em gênero ${ }^{15}$. Contudo, em parte posterior ao relato das torturas, há a afirmação de que a militante recebia ameaças de que torturariam sua filha de 9 (nove) meses, ameaças que motivaram que a anistianda pedisse ao seu irmão que levasse sua filha para a Noruega, a fim de protegê-la. A conselheira ressalta, pensando na experiência vivenciada pela anistianda, a dor da distância da filha, a dor por não estar presente nos primeiros passos, nas suas primeiras falas. Exemplificamos essa sensibilização provocada na conselheira a partir do trecho a seguir:

Com o objetivo de manter sempre o contato com a filha, escrevia cartas, em formas de desenho, pois a filha tinha pouquíssima idade. No entanto, eram censuradas, porque poderiam ser códigos endereçados aos subversivos em liberdade (Brasil, 2013, p. 245).

Em Jamais o Fogo Nunca, romance ficcional, a personagem principal é uma ex-militante política que atuou na oposição à ditadura imposta através de golpe militar por Augusto Pinochet, no Chile, em 1973. O romance é desenvolvido através de seu olhar, um monólogo, em que se acompanham seus pensamentos, lembranças, rotina diária, seu relacionamento com o companheiro, ex-militante, agora recluso em um quarto. Ao decorrer do livro, percebemos algumas estruturas de atuação enquanto oposição, como a organização em células, tanto da militância quanto da compreensão da própria narradora a respeito do casamento, por exemplo:

\footnotetext{
${ }^{15}$ Por exemplo, nudez forçada, espancamentos na altura dos seios, violência sexual ou ameaça, cobras colocadas sobre o corpo, além de ameaçar torturar as mães, com quem as militantes possuíam fortes laços afetivos (Souza, 2012, p. 20).
} 
Para a narradora, o casamento é 'uma organização primitiva, geradora da pior classe de exploração' e, na versão dela, o matrimônio parece reproduzir, na relação dos gêneros, a hierarquização e a opressão que existia na 'célula revolucionária', a despeito da opressão que a organização tentava precisamente combater. Nos jogos de significantes criados pela narradora, além da continuidade criada entre a célula revolucionária e a célula familiar que espelha e inverte sua funcionalidade, o corpo individual e sua deterioração também parece remeter ao corpo social deteriorado (Klinger, 2018, p. 189-190).

Em relação às similaridades possibilitadoras de alguma aproximação, a narradora também havia sido presa, em razão de sua militância política, conforme trecho abaixo:

Mas quando saí da reclusão, ali estava Ximena. Ao me ver, cuidou até da direção, do matiz, da ênfase do olhar. Nunca se permitiu manifestar nem a menor emoção diante do que eu friamente já tinha lhe comunicado. Em vez disso tendeu a expressar sua satisfação porque uma militante saía em vida, eu saía à rua e ela estava à minha espera para me transportar ao lugar que tinha conseguido, um espaço, um espaço. Um lugar seguro, ela disse (Eltit, 2017, p. 142).

Também a obrigatoriedade da vida clandestina apresenta a possibilidade de aproximação, tendo no romance um destino trágico. Ao longo da leitura algo vai se desvelando, aos poucos, no emaranhado das lembranças alcançadas através de pensamentos desconexos, não lineares, a existência de um filho, menino de dois anos de idade, ou seria a não existência dessa criança que é ressaltada ao longo do texto? Após algumas afirmativas indiretas, a morte trágica desse filho surge nas páginas do livro. A narradora, então, nos faz compreender que a causa dessa morte trágica foi o impedimento de levar a criança ao hospital, em razão da vida clandestina a qual os três, ela, o companheiro e o filho, estavam obrigados. Pelos fatos narrados, compreende-se que a criança desenvolveu algum tipo de infecção, que lhe causava febres, e pela ausência de atendimento médico e, consequentemente, do tratamento adequado, a doença progride até o fim, com a morte do filho, trauma que aparece frequentemente, ainda que entre linhas, ao longo da narrativa.

Característica de regimes autoritários, a proibição de uma atuação contra o regime político, implica no uso de instituições do direito para perseguir os seus opositores. A experiência de rupturas institucionais e tentativas de retorno democrático na América-Latina, e nos casos aqui discutidos, Brasil e Chile, permitiu estudiosos perceberem certas características em comum, mesmo considerando as especificidades de cada um. A "escolha" pela clandestinidade gera consequências diversas nas vidas dos opositores políticos e de seus familiares ${ }^{16}$.

No caso das mulheres resistentes e perseguidas políticas, há uma atenção aos resultados dessa perseguição no que concerne à maternidade e aos seus direitos reprodutivos de forma mais generalizada. Contudo, a violação baseada em gênero mais pesquisada, com literatura mais farta, que abrange tanto pesquisas relacionadas a reparações pecuniárias como ao próprio direito penal

\footnotetext{
${ }^{16} \mathrm{O}$ termo escolha está entre aspas em razão de a autora não compreender como de fato um resultado da autonomia da vontade pessoal dos opositores ao regime, e sim uma imposição dadas as condições das ameaças e perseguições, prisões extrajudiciais, torturas, desaparecimentos forçados perpetrados por agentes do Estado.
} 
internacional é a violação sexual. Os dois pareceres aqui discutidos foram selecionados por tratarem também da questão da maternidade, tema em que a aproximação com o texto ficcional era possível, mas chama a atenção o fato de que nenhum dos dois sequer menciona a questão da violência sexual, nem como uma ameaça. Já no texto ficcional o tema aparece, através de uma insinuação da possibilidade de o filho ser resultado de um estupro, "Estava preparada para sopesar todas e cada uma das condições e o menino em mim. O cativeiro, o menino e eu" (Eltit, 2017, p. 142):

A narradora também sugere, mas não afirma, que o filho poderia ser fruto da violência, do estupro que a narradora sofrera no tempo em que esteve presa (o marido pergunta sobre o filho 'de quem é? De quem é?', e ela responde 'de qualquer um, de todos, que importa'); ela fantasia com a ideia, cujo grau de paranoia é difícil de determinar, de que o marido desejasse sua morte durante o parto, não procurando ajuda no momento em que ela quase se dessangrava (Klinger, 2018, p. 190).

Assim, compreende-se que no romance chileno, obra ficcional, e nos pareceres da CA/MJ analisados são abordados temas que têm em comum o contexto de repressão política, as ditaduras brasileira e chilena, e o foco de atenção direcionado às vivências de mulheres militantes políticas. Apesar da diferença ente ambos, uma obra ficcional e um livro com pareceres de conselheiros de uma Comissão de Estado, oficial e documental, é possível perceber algumas recorrências, como a maternidade como um dos temas centrais.

\section{Considerações finais}

As discussões trabalhadas nesse artigo partem de uma pesquisa em desenvolvimento, na qual se analisam os pareceres elaborados pelos conselheiros da Comissão de Anistia Política a respeito de pedidos formulados por mulheres militantes que sofreram violações a direitos humanos durante a ditadura civil-militar brasileira (1964-1985). Tem como objeto uma publicação oficial em que determinados pareceres foram selecionados para representar os vários grupos que se colocaram contra o regime autoritário, como as mulheres, conforme descrito na publicação e citado anteriormente. Assim, para discutir a relação entre violações baseadas em gênero e reparação às mesmas, no contexto brasileiro, partiu-se da compreensão de que o projeto constitucional inaugurado em 1988, aberto e

que se lança ao futuro, se pretendeu comprometido com o Estado Democrático de Direito. É nesse sentido, de uma transição política de um regime autoritário para um Estado democrático que se delineiam medidas para lidar com esse passado de graves violações a direitos humanos e crimes contra a humanidade. Os programas de reparação a essas violações fazem parte dos mecanismos tradicionais que servem como guia para a transição política.

Contudo, partindo da perspectiva das teorias feministas, apresentaram-se críticas à justiça de transição, segundo as quais foi desenvolvida em um âmbito masculino e masculinizado, no contexto do direito internacional, relegando a experiência e a vivência das mulheres a segundo plano, se tanto. Afirmam que houve um silenciamento das mesmas e uma exclusão das mulheres dos âmbitos de decisão, desenvolvimento e implementação dessas medidas para a transição, e que essa exclusão resulta em um processo injusto e que possibilitaria a permanência da estrutura social em que se assenta a desigualdade entre os gêneros. Assim, a justiça de transição deixaria de corresponder ao seu potencial de transformação no que se convencionou chamar de justiça de gênero. 
Essas críticas feministas começaram a surtir efeito no direito internacional penal, através das conquistas do entendimento segundo o qual o estupro cometido em contextos de conflito armado e regimes autoritários, fosse tipificado como crime contra a humanidade e genocídio. Apesar de se compreender como um avanço, essa discussão centrada na violência sexual sofrida acaba por reduzir a vivência das mulheres perseguidas à sua sexualidade, ignorando todas as outras formas que elas podem ter seus direitos humanos violados pelo Estado, como no caso brasileiro.

Em um segundo momento desses avanços, as atenções se voltam aos programas de reparação, seriam eles capazes de possibilitar uma modificação na estrutura desigual da sociedade? Para responder essa pergunta, a perspectiva feminista no âmbito da justiça transicional colaborou para o delineamento de reparações que fossem sensíveis a gênero. Ou seja, capazes de responder a contento aos desígnios de uma justiça de gênero, que não apenas se ocupasse de um retorno ao status quo, mas que assumisse seu comprometimento com um Estado que seja de fato democrático. Nesse âmbito que se pensaram quais seriam aquelas violações a direitos humanos cometidas contra mulheres, dada a sua especificidade como mulher. Um parêntese se torna necessário pois não se ignora como pode ser redutora de experiências e sujeitos a tentativa de limitar esse sujeito mulher com determinadas características específicas. Algumas escolhas metodológicas se impuseram dado o tema trabalhado, como o livro, objeto da análise, não aborda em momento algum a diversidade sexual, de classe ou de raça, há um total silenciamento, como se se tratassem de sujeitos universais. Só é possível saber que se tratam de mulheres e homens, nessa leitura hegemônica, cisgênera, e racista em razão da alteração na ortografia, em substantivos, adjetivos que são enquadrados como masculinos ou femininos.

Dessa forma, dada a impossibilidade de uma análise diversa, selecionamos dois dos pareceres para compreendermos como as ditas violações baseadas em gênero seriam tratadas para então tentar realizar uma aproximação de Jamais o Fogo Nunca, em uma metodologia do direito e literatura. Duas características aqui preliminarmente discutidas relacionam-se a associação frequente das mulheres e da maternidade e da imposição da clandestinidade através do aparato do Estado. Os objetos analisados apresentaram em seu conteúdo essas associações de forma clara e reiterada, como se um confirmasse o outro. Seria possível pensar em algumas hipóteses para tanto, mas principalmente no que tange a divisão sexual do trabalho, em que o trabalho de reprodução e de cuidado cabe à mulher, e por isso essa associação estaria assim de modo tão evidente.

Por ser um resultado ainda preliminar, as análises ainda estão sendo desenvolvidas de forma mais aprofundada, mas um outro ponto a ser melhor pensado relaciona-se a ausência de menção a violência ou ameaça de violência sexual nos pareceres publicados pela CA/MJ. A literatura especializada ressalta com alarde que essa seria a violação baseada em gênero que mais foi tratada, tanto no âmbito penal, quanto nas reparações. É muito interessante que sequer se fale nelas, mas uma menção reiterada no que tange à mulher e maternidade. Ao contrário, a obra da qual se buscou aproximar, há o estupro, o filho que nasce como resultado do mesmo. Apesar de interessantíssima, essa discussão será melhor aprofundada em outra oportunidade.

Assim, conclui-se que a temática das violações cometidas por regimes autoritários e como elas impactam na vida daqueles que se opõem a ele foram ressaltados nos pareceres analisados e na obra da qual tentou se realizar a aproximação. Ainda, que houve similaridades temáticas no que se refere às violações que são mais comumente associadas às mulheres e suas vivências como perseguidas políticas. 


\section{Referências}

ALVAREZ, Sonia E. Para Além da Sociedade Civil: reflexões sobre o campo feminista. Cadernos Pagu, n. 43, p. 13-56, 2014. Disponível em:

https://periodicos.sbu.unicamp.br/ojs/index.php/cadpagu/article/view/8645074. Acesso em: 04 jan. 2019.

ARTHUR, Paige. How Transitions Reshaped Human Rights: A Conceptual History of Transitional Justice. Human Rights Quarterly, v. 31, n. 2, p. 321-367, 2009.

BAILEY, Paz; PAZ, Claudia. Guatemala: gender and reparations for human rights violations. In: RUBIO-MARÍN, Ruth (Ed.). What Happened to the Women? Gender and Reparations for Human Rights Violations. International Center for Transitional Justice. New York: Social Science Research Council, 2006.

BARBA, Mariana; WENTZEL, Marina. Discurso de Bolsonaro deixa ativistas 'estarrecidos' e leva $O A B$ a pedir sua cassação [Online]. BBC News, 2016. Disponível em:

https://www.bbc.com/portuguese/noticias/2016/04/160415_bolsonaro_ongs_oab_mdb. Acesso em: 02 set. 2017.

BRASIL. Ministério da Justiça e Cidadania. Comissão de Anistia. Livro dos Votos da Comissão de Anistia: verdade e reparação aos perseguidos políticos no Brasil [Online]. Ministério da Justiça e Cidadania, Comissão de Anistia. Brasília/Florianópolis: Comunicação, Estudos e Consultoria, 2013. Disponível em: http://www.justica.gov.br/central-de-conteudo/anistia/anexos/livro-dos-votosversao-final-20-08-2013.pdf. Acesso em: 02 set. 2017.

CAMARGO, Ayla. Nas origens do movimento feminista "revisitado" no Brasil. O Círculo de Mulheres de Paris [Online]. Anais do I Simpósio sobre Estudos de Gênero e Políticas Públicas, 2010. Disponível em: http://www.uel.br/eventos/gpp/pages/arquivos/8.AylaCamargo.pdf. Acesso em: 26 jun. 2019.

CARVALHO NETTO, Menelick; SCOTTI, Guilherme. Os Direitos Fundamentais e a (In)Certeza do Direito: A produtividade das tensões principiológicas e a superação do sistema de regras. Brasília: Editora Fórum, 2012.

CATTONI DE OLIVEIRA, Marcelo Andrade. Contribuições para uma Teoria Crítica da Constituição. Belo Horizonte: Arraes Editora, 2017.

. Democracia Sem Espera e Processo de Constitucionalização: Uma Crítica aos Discursos Oficiais sobre a Chamada "Transição Política Brasileira". Revista Anistia Politica e Justiça de Transição, n. 3, p. 200-229, 2010.

COMISSÃO DA ANISTIA. Livro dos votos na Comissão da Anistia: verdade e reparação aos perseguidos políticos no Brasil. Brasília/Florianópolis: Comunicação, Estudos e Consultoria, 2013. Disponível em: https://www.justica.gov.br/central-de-conteudo/anistia/anexos/livro-dos-votosversao-final-20-08-2013.pdf. Acesso em: 26 jun. 2019.

COMISSÃO NACIONAL DA VERDADE. Relatório da $C N V$ [Online]. 2014. Disponível em: http://cnv.memoriasreveladas.gov.br/. Acesso em: 05 fev. 2019. 
DALTON, Clare. Where we stand: observations on the situation of feminist legal thought. Berkeley Journal of Gender, Law \& Justice, v. 3, n. 1, p. 1-13, 2013. Disponível em: https://scholarship.law.berkeley.edu/bglj/vol3/iss1/1/. Acesso em: 11 nov. 2018.

DAVIS, Agela. Mulheres, raça e classe. São Paulo: Boitempo, 2016.

DE GREIFF, Pablo. The Handbook of Reparations. New York: Oxford University Press/The International Center of Transitional Justice, 2006.

DUARTE, Constância L. Feminismo e literatura no Brasil. Revista da USP - Estudos Avançados, v. 17, n. 49, p. 151-172, 2003. Disponível em: http://www.revistas.usp.br/eav/article/view/9950. Acesso em: 15 jan. 2019.

ELTIT, Diamela. Jamais o fogo nunca. Belo Horizonte: Relicário Edições, 2017.

FRANCO, Mariana. Do terrorismo de Estado à violência estatal: problemas históricos e historiográficos no caso argentino. In: MOTTA, Rodrigo Patto Sá (Org.). Ditaduras Militares: Brasil, Argentina, Chile e Uruguai. Belo Horizonte: Editora UFMG, 2015.

GIANORDOLI-NASCIMENTO, Ingrid Faria. Mulheres e militância: encontros e confrontos durante a ditadura militar. Belo Horizonte: Editora UFMG, 2012.

GIANORDOLI-NASCIMENTO, Ingrid Faria et al. A Construção da memória histórica da ditadura militar brasileira: contribuição das narrativas de familiares de presos políticos. Psicologia e Saber Social, v. 1, n. 1, p. 103-119, 2012. Disponível em: http://www.e-publicacoes.uerj.br/index.php/psisabersocial/article/view/3249/2258. Acesso em: 01 set. 2017.

HARAWAY, Donna. Saberes localizados: a questão da ciência para o feminismo e o privilégio da perspectiva parcial. Cadernos Pagu, n. 5, p. 7-41, 2009. Disponível em:

https://periodicos.sbu.unicamp.br/ojs/index.php/cadpagu/article/view/1773. Acesso em: 02 jan. 2019.

HENRY, Astrid. Not My Mother's Sister: Generational Conflict and Third-Wave Feminism. S.l.: Indiana University Press, 2004.

HORKHEIMER, Max. Teoria tradicional e teoria crítica. In: Benjamin, Horkheimer, Adorno, Habermas. São Paulo: Abril Cultural, 1975. Coleção Os Pensadores.

JOFFILY, Mariana. Violências Sexuais nas Ditaduras Militares Latino-Americanas: Quem Quer Saber? Revista Internacional de Direitos Humanos, v. 13, n. 24, p. 165-176, 2016. Disponível em: http://sur.conectas.org/violencias-sexuais-nas-ditaduras-da-al-quem-quer-saber/. Acesso em: 26 jul. 2017.

KLINGER, Diana. A Resistência: uma vida. ALEA: Estudos Neolatinos, v. 20, n. 2, p. 184-195, 2018. Disponível em: https://revistas.ufrj.br/index.php/alea/article/view/18672. Acesso em: 14 jan. 2019.

KOEDT, Anne. The Myth of the Vaginal Orgasm. In: KOEDT, Anne; LEVINE, Ellen; RAPONE, Anita Rapone (Eds.). Radical Feminism. New York: Quadrangle, 1973.

MACKINNON, Catharine A. Toward a Feminist Theory of the State. Cambridge: Harvard University Press, 1989.

MEYER, Emilio Peluso Neder. Ditadura e Responsabilização: elementos para uma justiça de transição no Brasil. Belo Horizonte: Arraes Editores, 2012.

NARVAZ, Martha Giudice; KOLLER, Sílvia Helena. Metodologias feministas e estudos de gênero: articulando pesquisa, clínica e política. Psicologia em Estudo, v. 11, p. 647-654, 2006. Disponível 
em: http://www.scielo.br/scielo.php?script=sci_abstract\&pid=S1413-

$73722006000300021 \& \operatorname{lng}=$ en\&nrm=iso\&tlng=pt. Acesso em: 26 jun. 2019.

PEREIRA, Anthony W. Ditadura e Repressão: o autoritarismo e o estado de direito no Brasil, no Chile e na Argentina. São Paulo: Paz e Terra, 2010.

RIBEIRO, Djamila. O que é lugar de fala? Belo Horizonte: Letramento, 2017.

RUBIO-MARÍN, Ruth. The Gender of Reparations: Setting the Agenda. In: RUBIO-MARÍN, Ruth (Ed.). What Happened to the Women? Gender and Reparations for Human Rights Violations. International Center for Transitional Justice. New York: Social Science Research Council, 2006.

SOUZA, Lídio. Prefácio. In: GIANORDOLI-NASCIMENTO, Ingrid Faria. Mulheres e militância: encontros e confrontos durante a ditadura militar. Belo Horizonte: Editora UFMG, 2012.

TEITEL, Ruti G. Transitional Justice. Nova Iorque: Oxford University Press, 2002.

TELES, Maria Amélia de Almeida. Breve História do Feminismo no Brasil e outros ensaios. São Paulo: Editora Alameda, 2017.

WOLLSTONECRAFT, Mary. Reivindicação dos Direitos da Mulher. São Paulo: Boitempo, 2016.

Artigo recebido em: Março/2019

Artigo aprovado em: Julho/2019

Raquel Cristina Possolo Gonçalves (possolo.raquel@gmail.com) é Mestranda em Direito pela Universidade Federal de Minas Gerais (UFMG).

Jéssica Holl (jessica_holl@ymail.com) é professora na Universidade Federal de Ouro Preto (UFOP). Mestre em Direito pela Universidade Federal de Minhas Gerais (UFMG).

\section{“Já Não Estamos Exatamente Vivos" - pareceres da CA/MJ e possíveis aproximações de Jamais o Fogo Nunca}

Resumo. O presente trabalho é parte de uma pesquisa maior, ainda em desenvolvimento, que busca compreender, através das teorias feministas e suas críticas a justiça de transição, as reparações a violações a direitos humanos baseadas em gênero que foram perpetradas por agentes da ditadura brasileira (1964-1985). Tem como foco reparações a mulheres dissidentes políticas, perseguidas pelo regime. Na perspectiva de uma crítica feminista a justiça de transição, compreende-se que em regimes autoritários e no contexto de graves violações a direitos humanos, várias violações são cometidas contra mulheres pelo fato de serem mulheres. Assim, partindo dessa perspectiva, no trabalho em desenvolvimento busca-se perceber como essas violações baseadas em gênero são tratadas pelo programa de reparação brasileiro, Comissão de Anistia do Ministério da Justiça, através da análise de dois pareceres publicados no Livro dos Votos (Comissão de Anistia/MJ). Nesse sentido, complementando essa pesquisa em andamento, apresenta-se aqui uma tentativa de aproximação com a literatura ficcional que tem como contexto também um regime autoritário, através de alguns trechos do romance Jamais o Fogo Nunca, de Diamela Eltit. O monólogo em análise foi escolhido em razão de ter como personagem principal uma mulher que militou contra a ditadura chilena, regime 
autoritário instaurado por Augusto Pinochet, através de golpe militar, em 1973. Ressalta-se que nesse momento, apesar de não serem ignoradas, as especificidades de cada contexto histórico não serão tratadas de forma pormenorizada, a fim de que a abordagem se atenha às características das violações perpetradas contra as mulheres.

Palavras-chave: Justiça de Transição; Reparações; Violações baseadas em Gênero; Ditadura.

\title{
"We are not Exactly Alive" - the Amnesty Commission of the Ministry of Justice's Legal Advice (CA/MJ) and their relationship with "Jamais o Fogo Nunca"
}

\begin{abstract}
This article is part of a larger research, still in development, that seeks to understand, through feminist theories and its criticisms of transitional justice, reparations to human rights violations based on gender that were practiced by agents of the Brazilian dictatorship (1964-1985). It focuses on reparations to dissident political women pursued by the regime. In the perspective of a feminist critique of transitional justice, researchers have affirmed that in authoritarian regimes and in the context of serious human rights violations, several violations are committed against women because they are women. Thus, starting from this perspective, the work in development seeks to understand how the Brazilian reparations program, the Amnesty Commission of the Ministry of Justice, handles these gender-based violations, through analyses of a vows book (published by Amnesty Commission). In this sense, complementing this ongoing research, we present here an attempt to approach the fictional literature that has as context also an authoritarian regime, through some passages of the novel Jamais o Fogo Nunca, by Diamela Eltit. We choose the monologue in analysis because it has as main personage a woman who militated against the Chilean dictatorship, authoritarian regime established by Augusto Pinochet, through military coup, in 1973. We emphasize that at this moment, although not ignored, the specificities of each historical context will not be dealt with in detail so that the approach addresses the characteristics of the violations perpetrated against women.
\end{abstract}

Keywords: Transitional Justice; Reparations; Gender-Based Violations; Dictatorship. 